\title{
Firm Utilization of Perceived Obsolescence
}

\section{Ace Kim}

Northern Valley Regional High School at Old Tappan

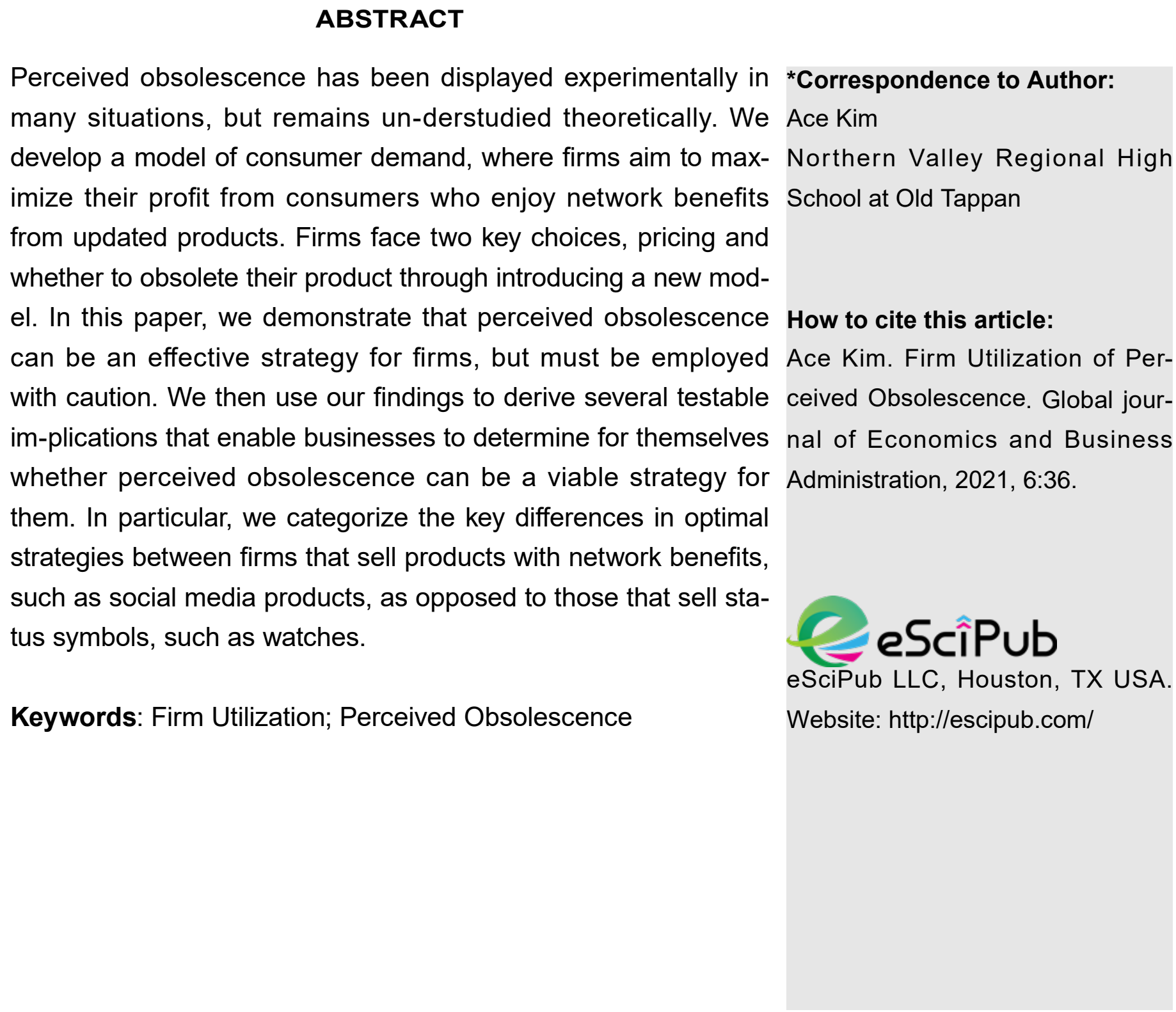




\section{Introduction}

Coined in 1932, the term "planned obsolescence" refers to the deliberate limitation of a product's useful lifespan in order to encourage repeat purchases. Limiting the usefulness of products can occur in two key ways: manufactured and perceived obsolescence. Manufactured obsolescence refers to designing the product to physically deteriorate over time. On the other hand, perceived obsolescence refers to decreasing the desirability of older products through developing novel aesthetic styles for newer products.

Planned obsolescence on a large scale was first seen in the 1920s with the Phoebus Cartel - a then global lightbulb cartel. The Phoebus Cartel took collective action to limit the lifespan of all lightbulbs on the market. The cartel succeeded in reducing the average lightbulb lifespan down to 1000 hours, increasing the rate of consumer repurchase (Krajewski, 2014) [5]. The term, "planned obsolescence," was popularized in 1932 with Bernard London's paper, Ending the Depression Through Planned Obsolescence (London, 2014) ${ }^{[7]}$. London argued that the best way to lift America out of the Great Depression would be to "assign a lease of life to shoes and homes and machines." He believed that "new products would constantly be pouring forth from the factories and marketplaces, to take the place of the obsolete" and that this new demand would create jobs and stimulate the economy. However, the use of planned obsolescence in the modern day tends to be far less utilitarian in nature.

Today, different types of planned obsolescence can be found in almost every major industry. A key example of both perceived and manufactured obsolescence would be fast fashion. Many corporations like Zara and H\&M pump out "12 to 24 collections every year." These collections feature radically unique styles and trends, each of which are designed to die off quickly (Lewis, 2020) [6]. Because consumers desire to wear clothing that fits the latest style or trend, previously purchased older products become obsolete. Additionally, these companies also purposefully lower the lifespan of their cloths by designing them to fade or wear down more quickly than they should (Lewis, 2020) ${ }^{[6]}$. Through these two strategies, the fashion industry is able to increase sales and profits at the cost of the environment.

Manufactured obsolescence has been widely studied as a corporate strategy, and its effectiveness for businesses has been displayed experimentally. However, perceived obsolescence, the now more prevalent form of planned obsolescence, remains widely understudied. To determine the effectiveness and impact of perceived obsolescence in different industries, we develop a model of consumer demand where firms aim to maximize their profit. Importantly, consumers face network effects in their enjoyment of the good, dependent upon the number of other consumers that have also purchased and updated the good. The network effects represent the gains or losses a consumer faces in terms of social status when they fit the crowd. The firms face two key choices: pricing and whether to obsolete their product through introducing a new update. The solutions we derive from our model demonstrate how effective perceived obsolescence can be in different industries, what conditions must be met for perceived obsolescence to be effective, and how businesses can determine for themselves whether perceived obsolescence is a viable strategy for them.

Overall, we find that in the absence of competition, firms maximize their expected profit in their initial product sale by extracting all surplus from the consumer. We determine that firms can maximize their profit by devising a price based upon the expected network benefit. Finally, we find that the nature of the network effect heavily affects how firms should price their products. When the network effect is nondecreasing, firms should aim to sell their products to a large audience. However, when the network effect is decreasing, firms should limit the quantity of the product sold by adjusting 
the price to increase its exclusivity.

\section{Literature Review}

The economic study of planned obsolescence began with Bulow (1986) [1]. They study a monopoly that sells a durable good over an infinitely repeated time period. The key constraint faced by the monopolist is a lack of commitment. After selling at a given price, the monopolist faces a strong incentive to cut the price in the following period as a form of price discrimination. Anticipating this, consumers delay their purchasing decisions. To avoid the commitment issue, the firm engages in planned obsolescence to allow for repeated surplus extraction.

While there is little economic work done on perceived obsolescence from a theoretical stand-point, several empirical studies exist. Fels et al. (2016) [2] studies obsolescence from a consumer standpoint. Through extracting reviews from Amazon, the authors show a categorical differ-ence in consumer repurchasing decisions between physical goods and electronic products. For instance, while only 13 out of 61 consumers with obsoleted vacuums purchased the same brand later on, 20 out of 28 with obsoleted phones did the same. Furthermore, of the 13 that re-purchased a brand with obsoleted vacuums, 11 of those who did so attributed the repurchase decision to "wear out", as opposed to "ergonomics" or "changing needs". Their study strongly suggests that the decision to engage in perceived versus manufactured obsolescence is indus-try specific and should depend upon the consumer's perception of the product in question. In particular, while a consumer's old vacuum may not be visible to their friends and peers, it is difficult to hide an old phone when it is constantly necessary for modern life.

Related to our model, Koca et al. (2021) ${ }^{[4]}$ study a firm that needs to simultaneously attract new consumers while convincing old consumers to upgrade. Their firm's primary choice is the decision regarding when to discontinue the old product and roll it into a new one. Key to their results is the imposition of naivety upon certain consumers, those consumers fail to take into account future firm decisions regarding their welfare. We focus on rational consumers that correctly anticipate the future, generating different implications for optimal firm pricing.

\section{General Model}

We consider a model where a firm sells a good to $\mathrm{N}$ consumers, then must decide how and when to offer updates for that good. Time is discrete, $t \in\{0,1,2, \ldots\}$, the firm and consumers share a discount factor $\delta$. When $t=0$, the firm chooses a price, $p$, at which to sell the good. We assume the firm faces a constant marginal cost, namely the firm pays a cost $c$ for each unit it sells. Each consumer then simultaneously chooses whether they wish to purchase the good. Consumers that do not purchase the good receive their outside option worth utility $u_{0}$, and

cease to interact with the firm. If consumer $i$ purchases the good she pays $p$, and her choice is

represented by $b_{i}=1$, otherwise $b_{i}=0$.

A consumer that has purchased the good receives $\theta$ in utility immediately. In addition, if $n$ other consumers have also purchased the good, the consumer receives an additional utility adjustment in the form of $f(n)$. Later, we place further assumptions upon the form of $f(n)$ to motivate our results. Importantly, we do not assume here that $f(n)$ is an increasing function. Indeed, we show the optimal strategy varies wildly when $f(n)$ is non-monotonic as opposed to increasing in our results section.

In every period except for $t=0$, the firm may choose to engage in perceived obsolescence, $\omega_{t}$ $\epsilon\{0,1\}$. If the firm engages in perceived obsolescence, $\omega_{t}=1$, the firm chooses a new price $p_{t}$ to charge for updates in period $t$. All consumers who originally purchased the good may choose to purchase the updates at cost $p_{t}$, their choice is indicated by $\omega_{t}^{i} \in\{0,1\}$. The firm pays a cost $c_{u}$ for each consumer that purchases the update. Consumer that have updated their good since the most recent time the firm 
engaged in perceived obsolescence receive $f(n)$ where $n$ is the number of other consumers that have also updated their good.

Consumer utility is quasilinear in money, i.e. the discounted sum of per period utility minus their total payments. A firm's utility is given by their discounted profit, namely the discounted sum of all consumer payments minus the cost of production:

$$
\pi=\sum_{i}\left[b_{i}(p-c)+\sum_{t} \delta^{t} \omega_{t}^{i}\left(p_{t}-c_{u}\right)\right] .
$$

\section{Results}

\section{Increasing Network Effect Example}

We begin by describing a simple example to provide the main intuition for our model when $f(n)$ is increasing. The firm sells a good to $N=2$ consumers. There are two periods, $t \in\{1,2\}$. Again, when $t=1$, the firm chooses a price, $p$, at which to sell the good, and each of the two consumers simultaneously choose whether they wish to purchase the good. Consumers that do not purchase the good receive their outside option worth utility $u_{0}$, and cease to interact with the firm. A consumer that purchases the good pays $p$.

A consumer that has purchased the good receives $\theta$ in utility immediately. In addition,

if the other consumer has also purchased the good, the consumer receives a bonus, $f$. If the other consumer has not purchased the good, no bonus is received. ${ }^{1}$ Consumer i's utility from purchasing the good in the first period is then:

$$
u_{1}^{i}\left(b_{i}=1\right)=-p+\theta+f 1_{b_{-i}}
$$

In the second period, the firm decides whether to engage in perceived obsolescence $\omega_{2} \in\{0,1\}$. If $\omega_{2}=0$, consumers who have purchased the good receive $u_{2}\left(b_{i}=1\right)=f 1_{b_{-1}=1}$. If $\omega_{2}=1$, the firm determines the price to update $p_{2} \in \mathrm{R}^{+}$. When $\omega_{2}=1$, consumers that

originally purchased the good may choose to update their good by paying cost $p_{2}$. Consumer i's utility in the second period conditional upon purchasing the update is once more a function of the update price and the network effect:

$$
u_{2}^{i}\left(\omega_{2}^{i}=1\right)=-p_{2}+f 1_{\omega_{2}^{-i}}
$$

The firm's profit is a function of the amount they price the good in each period, the cost to manufacture the good in each period, and whether the consumer chooses to buy or update the good in each period. The firm's profit is given by:

$$
\pi=(p-c) \sum_{i} 1_{b_{i}}+\left(p_{2}-c_{u}\right) \sum_{i} 1_{\omega_{2}^{i}}
$$

Because the network effect is increasing, the firm wishes to onboard both consumers in the first period by setting a price below the consumer's total surplus. Through doing so, the firm can then obsolete the good in the second period, and charge both consumers for an update.

Proposition 1. Let $f>c_{u}$ and $\theta+f-u_{\text {out }}-c+f-$ $c>0$.

Then, the following strategy profile is a subgame perfect equilibrium:

$$
\begin{aligned}
p & =\theta+f-u_{\text {out }} \\
p_{2} & =f,
\end{aligned}
$$

and both consumers purchase the good if $p$ is equal to or below the above values, then purchase updates in the second period if $p_{2}$ is equal to or below the above.

Proof. Begin by considering the consumers' possible deviations. First, a consumer could deviate by not purchasing the good in the first period. Doing so yields uout in utility to that consumer. However, the consumer already

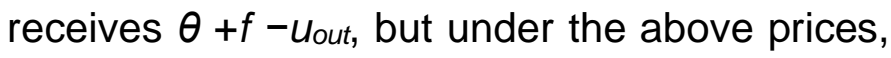
this implies the consumer receives uout in utility. Therefore, opting to not purchase the good is not a profitable

deviation. Next, a consumer could deviate by avoiding an update in the second period. Again, their utility from doing so is 0 in that period, while their utility otherwise is also 0 . Last, we check for off the equilibrium path deviations, namely if the

${ }^{1}$ In the general notation, this corresponds to $f(1)=f$ and $f(0)=0$. 
firm over or under charges in a given period relative to the equilibrium benchmark. If the firm overcharges, consumers who deviate by purchasing or updating then have an expected utility less than zero, which is a negatively profitable deviation. If the firm under charges, consumers that deviate by failing to purchase or update give up a strictly positive payoff in return for 0 .

The key features of this example hold up in the general model. Importantly, when $f(n)$ is increasing, the firm maximizes profit by onboarding all consumers. However, in doing so, the firm breaks up the actual cost of the good over multiple periods. Rather than charging the consumer everything up front, it charges the consumer piecemeal with costly updates. We return to the general model for the following theorem.

Theorem 1. Let $f(N-1)>C_{u}$ and $\theta+f(N-1)-$ Uout $-c+\mathrm{P}_{t=1}^{\infty} \delta^{t} f(N-1)>c$.

When $f(n)$ is non-decreasing in $n$, the following is a sub-game perfect equilibrium:

$$
\begin{aligned}
p & =\theta+f(N-1)-u_{\text {out }} \\
p_{t} & =f(N-1) .
\end{aligned}
$$

All consumers purchase the good if $p$ is equal to or below the above definitions, then purchase updates in every period if $p_{t}$ is equal to or below the above.

Proof. To see that the firm cannot make further profits, note if the firm increases prices, consumers opt to not purchase and the firm makes zero profit. The following proof treads closely to the proof from the toy model.

Next, consider the consumers' possible deviations. First, a consumer could deviate by not purchasing the good in the first period. Doing so yields $u_{o u t}$ in utility to that consumer. However, the consumer already receives $\theta+f(N-1)$ - $u_{\text {out }}$ $-p+P_{t=1}^{\infty}\left[\delta^{t} f(N-1)-p_{t}\right]$, but under the above prices, this implies the consumer receives uout in utility. Therefore, opting to not purchase the good is not a profitable deviation. Next, a consumer could deviate by avoiding an update in a given period. Again, their utility from doing so is 0 in that period, while their utility otherwise is also 0 . Last, we check for off the equilibrium path deviations, namely if the firm over or under charges in a given period relative to the equilibrium benchmark. If the firm overcharges, consumers who deviate by purchasing or updating then have an expected utility less than zero, which is a negatively profitable deviation. If the firm under charges, consumers that deviate by failing to purchase or update give up a strictly positive payoff in return for 0 .

\section{Non-monotonic network effects}

To motivate this section, consider the following. Nike's exclusive shoes face non-monotonic network effects, where the price of their limited edition shoes is highly based on the quantity of that line of shoe on the market. Nike chooses to only make a very limited quantity, because they can then sell these shoes for a much higher value than their market cost. In particular, a firm may face a decreasing network effect when the appeal of their products is directly related to their rarity. In terms of the model, this implies that the network effect, $f(M)$, is decreasing. This leads to a stark difference in the optimal firm strategy. To determine how a firm's behavior should change in response to a decreasing network effect, we must first determine the firm's profit function. The firm's profit is the sum of the profit the firm makes in the first cycle, the profits the firm makes from updates, and the costs of producing or updating the product.

To narrow our focus to the impact of a decreasing $f(M)$, we assume that $c=C u=0$ and that $u_{\text {out }}=0$. We also assume that $\theta=2$ and that $\delta=\underline{2}^{1}$. Therefore, the firm's profit is given

by the following:

$$
\pi=p+\frac{1 / 2 p_{t}}{1-1 / 2}
$$

Similarly, we impose the following functional form on $f(M)$ :

$$
f(n)=-\frac{1}{10}(n-1)^{2}+1
$$


depend on this functional form, the trade-off faced by the firm is general to decreasing network effect functions. We then determine the profit made by the firm when the firm sells the product to $n$ consumers and sells updates to $n_{u}$ consumers.

$\pi\left(n, n_{u}\right)=n(2+f(n-1))+n_{u} f\left(n_{u}-1\right)$

Notably, the firm's profit function is additive in $n$ and $n_{u}$, as such, the firm optimizes both separately from one another. We proceed by finding the optimal value of $n$ and $n_{u}$ independently. For $n \in\{1, \ldots, 5\}$ we find that upon serving $n$ consumers, the firm generates $\{3.8,8$, $11.4,12.8,11\}$ in profit. This implies that it would be optimal for the firm to sell their product to only 4 consumers, as doing so maximizes profit in the first period.

We then examine the profit made by the firm through selling the updated product to $n_{u}$ consumers in future periods. Solving for update profit when $n_{u} \in\{1, \ldots, 5\}$ we find that upon serving $n_{u}$ consumers, the firm generates $\{.9,2$, $2.7,2.4, .5\}$ in profit. Then, the firm finds it

optimal to sell the updated product to only 3 consumers in the following periods.

Since $n=4$ maximized the firm's profit, selling to only 4 consumers in the first period was most strategic for the firm. Additionally, since $n_{u}=3$ maximized the firm's profit in the future

periods, selling the updated product to only 3 consumers was most strategic for the firm. To be specific, the firm sets their initial price at 2.6, and sets the price for updates at 6 .

Overall, we find that when $f(M)$ is decreasing, firms should only sell their product to a finite number of consumers to generate the most profit. We also find that the quantity of consumers the firm should sell their product to in the first cycle is not necessarily the quantity of consumers the firm should sell their updates to. These observations offer valuable insights for businesses thinking of implementing perceived obsolescence. Firms might focus on two market segments, one for the general product and another for add-ons or peripherals. For instance, in 2014 mobile games made $50 \%$ of profit on $0.15 \%$ of consumers Tassi (2014) ${ }^{[8]}$. Other markets with similar features include electronic goods and automotives, where a base price exists and peripherals contains upcharges.

The observations we made in solving the simpler model when $f(n)$ was non-monotonic can be broadened to fit our general model. Importantly, the functional form of $f(n)$ was not the critical piece of the agenda. To see this, consider the following theorem.

Theorem 2. Let $2 f(n-1)+n f^{\prime \prime}(n-1)<0$ for $n \in$ $[1, \infty)$, then the following is a sub-game

perfect equilibrium:

Let $n^{\prime}$ be the unique solution to Let $n^{\prime}$ be the unique solution to $n^{\prime}=-\frac{\theta+f\left(n^{\prime}-1\right)}{f^{\prime}\left(n^{\prime}-1\right)}$, then $n=\arg \max _{\left[n^{\prime}\right],\left[n^{\prime}\right]} \pi(n)$. Similarly, let $n u^{\prime}$ be the unique solution to $n_{u}^{\prime}=\frac{-f\left(n_{u}-1\right)}{f^{\prime}\left(n_{u}-1\right)}$, then $n_{u}=\arg \max _{\left\lfloor n_{u}^{\prime}\right\rfloor,\left\lceil n_{u}^{\prime}\right]} \pi\left(n_{u}\right)$

Then, with the above $\mathrm{n}$ and $\mathrm{n}_{\mathrm{u}}$ the following is a sub-game perfect equilibrium:

$$
\begin{aligned}
p & =\theta+f(n-1)-u_{\text {out }} \\
p_{t} & =f\left(n_{u}-1\right),
\end{aligned}
$$

and all consumers purchase the good if prices are equal to or below the above definitions, then purchase updates in every period.

Proof. The firm's profit is given by the following equation, where $n$ denotes the number of consumers that buy the good in period 1 and $n_{u}$ denotes the numbers that buy updates in each period.

$$
\pi\left(n, n_{u}\right)=n(\theta+f(n-1))+n_{u} \delta \frac{f\left(n_{u}-1\right)}{1-\delta}
$$

To find the value of $n$ and $n_{u}$ that maximizes profit, we must take the first-order conditions. Importantly, profit is additive in $n$ and $n_{u}$, the firstorder condition for each separately is necessary for an equilibrium. Notably, for unrestricted $f$, the first-order condition is necessary but not necessarily sufficient. Solving for $n$, we find the following necessary condition: 


$$
\begin{aligned}
\frac{\partial \pi}{\partial n} & =\theta+f(n-1)+n f^{\prime}(n-1)=0 \\
n & =-\frac{\theta+f(n-1)}{f^{\prime}(n-1)}
\end{aligned}
$$

We repeat the first-order condition for $n_{u}$ and find:

$$
\begin{aligned}
\frac{\partial \pi}{\partial n_{u}} & =\frac{\delta}{1-\delta}\left[f\left(n_{u}-1\right)+n_{u} f^{\prime}\left(n_{u}-1\right)\right]=0 \\
n_{u} & =\frac{-f\left(n_{u}-1\right)}{f^{\prime}\left(n_{u}-1\right)}
\end{aligned}
$$

However, this value isn't necessarily an integer, but $2 f^{\prime}(n-1)+n f^{\prime \prime}(n-1)<0$ for $n \in[1, \infty)$

implies that the second derivative of this term is negative and so it transitions smoothly from increasing to decreasing.

Importantly, the second derivative of $n f(n-1)$ is $2 f^{\prime}(n-1)+n f^{\prime \prime}(n-1)$ which is less than

zero by assumption. Therefore, each of $n$ and $n_{u}$ has a unique maximizer and profit is concave

in the two terms. Then, the optimal numbers of consumers to sell to for the firm are within plus or minus one of the computed values of $n$ and $n_{u}$.

Corollary 1. When $f$ is decreasing and concave, there exists a unique optimal number of consumers that the firm sells to.

\section{Conclusion}

In this paper, we have analyzed how perceived obsolescence can affect consumer choice and how businesses can determine whether perceived obsolescence is a viable strategy. We arrived at the conclusion that perceived obsolescence can be used to generate higher profit margins, though care should be taken in targeting a consumer group.

By testing our model of consumer demand, we observe that in the absence of competition, firms maximize their expected profit in their initial product sale by extracting all surplus from the consumer. We then determine that firms can maximize the profit generated from updates by devising a price based upon the expected network benefit. Through these findings, we conclude that implementing a strategy of perceived obsolescence maximizes the expected utility of firms over time.

Notably, we find that before firms can implement a strategy of perceived obsolescence, they must first determine the nature of the network effect in their specific industry. We find that when the utility generated by the network effect is nondecreasing with respect to the number of consumers with updates products, firms should aim to maximize their sales through targeting a broad audience. However, when the utility generated by the network effect decreases in the number of consumers with updated products, firms must limit the quantity of their products sold in the initial sale and in all further updates. In particular, they should choose to set the price above the sale maximizing price, in order to increase the exclusivity of their product. Through doing so, while fewer consumers demand the product, those that do buy in, spend more than enough to make up for the absence of their peers. Should the firm have reduced the price enough to encourage more consumers, each individual consumer would have valued the product far less.

There are several avenues for future research that develop our findings further. First, to narrow our focus to perceived obsolescence, we assumed away natural obsolescence. It would be interested to observe how the two forces interact in practice. The ideal pricing model for non-durable goods would consider natural obsolescence. Another avenue for future research would be deriving a method for how firms can determine the network effect function in practice. Although we measure how different types of network effect functions impact our general profit functions, we do not specify how firms should determine the nature of network effect function they face. Since the optimal strategy not only depends upon the function itself, but also its derivative, this is of crucial importance. One possible method of doing so would be to run test markets in different cities across a nation to observe differential demand.

The theory examined in this paper provides several testable predictions. First, we determine that when the network effect is decreasing with respect to the number of consumers, markups 
should be higher on updated products. By implementing higher prices on updated products, firms can sell their product to the optimal number of consumers while maximizing profit. Additionally, our model makes the prediction that in cases with increasing network effects such as social media, we should observe increases in prices as more consumers buy onto the product. A prime example of this prediction in practice would be Facebook. We can associate the "price" of using Facebook as the quantity of ads shown to consumers. Since the quantity of ads shown has dramatically increased with respect to the quantity of Facebook users, this lines up closely with our projections (Forman, 2020). Importantly, when the number of initial consumers is small for social media apps, the optimal strategy involves lower or nonexistent ads, to maximize onboarding. This lines up closely with advice given to new entrepreneurs, where the goal is to venture capital money in order to avoid charging consumers while in the start-up phase.

\section{Acknowledgements}

I thank Andrew Ferdowsian for his guidance and support in helping with the writing of this paper.

\section{References}

[1]. Bulow, Jeremy, "An economic theory of planned obsolescence," The Quarterly Journal of Economics, 1986, 101 (4), 729-749.

[2]. Fels, Antonia, Bj"orn Falk, and Robert Schmitt, "Social media analysis of perceived product obsolescence," Procedia CIRP, 2016, 50, 571576.

[3]. Forman, Laura, "Facebook Ads Could Be Reaching Saturation Point," https://www. wsj.com/articles/facebook-ads-could-bereaching-saturation-point-116061328072020.

[4]. Koca, Esma, Tommaso Valletti, and Wolfram Wiesemann, "Designing Digital Rollovers: anaging Perceived Obsolescence through Release Times," Production and Operations Management, 2021.

[5]. Krajewski, Markus, "The Great Lightbulb Conspiracy," https://spectrum.ieee.org/ the-greatlightbulb-conspiracy 2014.

[6]. Lewis, Sharon, "Planned Obsolescence, And Other Open Secrets Of The Fashion Industry," https://www.jumpstartmag.com/plannedobsolescence-fast-fashion/ 2020.

[7]. London, Bernard, "Ending the depression through planned obsolescence," Revue du MAUSS, 2014, pp. 47-50.

[8]. Tassi, Paul, "Why its scary when $0.15 \%$ of mobile gamers bring in $50 \%$ of the revenue," https://www.forbes.com/sites/insertcoin/2014/03/ 01/ why-its-scary-when-0-15-mobile-gamersbring-in-50-of-the-revenue/?sh=79b38ed 40659 2014. 